\title{
BMJ Open Mental illness, poverty and stigma in India: a case-control study
}

\author{
Jean-Francois Trani, ${ }^{1}$ Parul Bakhshi, ${ }^{2}$ Jill Kuhlberg, ${ }^{1}$ Sreelatha S Narayanan, ${ }^{3}$ \\ Hemalatha Venkataraman, ${ }^{4}$ Nagendra N Mishra, ${ }^{3}$ Nora E Groce, ${ }^{5}$ Sushrut Jadhav, ${ }^{6}$ \\ Smita Deshpande ${ }^{3}$
}

To cite: Trani J-F, Bakhshi P, Kuhlberg J, et al. Mental illness, poverty and stigma in India: a case-control study. BMJ Open 2015;5: e006355. doi:10.1136/ bmjopen-2014-006355

- Prepublication history for this paper is available online. To view these files please visit the journal online (http://dx.doi.org/10.1136/ bmjopen-2014-006355).

Received 12 August 2014 Revised 13 January 2015 Accepted 15 January 2015

CrossMark

For numbered affiliations see end of article.

Correspondence to Dr Jean-Francois Trani; jtrani@wustl.edu

\section{ABSTRACT}

Objective: To assess the effect of experienced stigma on depth of multidimensional poverty of persons with severe mental illness (PSMI) in Delhi, India, controlling for gender, age and caste.

Design: Matching case (hospital)-control (population) study.

Setting: University Hospital (cases) and National Capital Region (controls), India.

Participants: A case-control study was conducted from November 2011 to June 2012. 647 cases diagnosed with schizophrenia or affective disorders were recruited and 647 individuals of same age, sex and location of residence were matched as controls at a ratio of 1:2:1. Individuals who refused consent or provided incomplete interview were excluded.

Main outcome measures: Higher risk of poverty due to stigma among PSMI.

Results: $38.5 \%$ of PSMI compared with $22.2 \%$ of controls were found poor on six dimensions or more. The difference in multidimensional poverty index was $69 \%$ between groups with employment and income of the main contributors. Multidimensional poverty was strongly associated with stigma (OR 2.60, 95\% Cl 1.27 to 5.31), scheduled castes/scheduled tribes/other backward castes (2.39, 1.39 to 4.08), mental illness $(2.07,1.25$ to 3.41$)$ and female gender $(1.87,1.36$ to 2.58). A significant interaction between stigma, mental illness and gender or caste indicates female PSMI or PSMI from 'lower castes' were more likely to be poor due to stigma than male controls $(p<0.001)$ or controls from other castes $(p<0.001)$.

Conclusions: Public stigma and multidimensional poverty linked to SMI are pervasive and intertwined. In particular for low caste and women, it is a strong predictor of poverty. Exclusion from employment linked to negative attitudes and lack of income are the highest contributors to multidimensional poverty, increasing the burden for the family. Mental health professionals need to be aware of and address these issues.

\section{INTRODUCTION}

Mental health problems affect 450 million people worldwide, $80 \%$ in middle-income and low-income countries. In 2010, 2319000 persons died of mental and behavioural
Strengths and limitations of this study

There is little research on the effects of stigma and poverty in developing settings.

- Lack of employment and income are major contributors to multidimensional poverty for persons with severe mental illness (PSMI).

- Intensity of multidimensional poverty is higher for PSMI, particularly women with SMI and those from scheduled castes/scheduled tribes/ other backward castes.

- Stigma was operationalised through a single-item question rather than a multiple-item scale, and we could not assess reliability of this item. SMI was diagnosed for persons attending a public psychiatric department; PSMI not receiving medical treatment might be more marginalised and at greater risk of poverty than those receiving healthcare.

disorders. ${ }^{1}$ Mental health conditions account for $13 \%$ of the total burden of disease, $31 \%$ of all years lived with disability and are one of the four main contributors to years lived with disability. $^{2}{ }^{3}$ Schizophrenia and bipolar disorder represent $7.4 \%$ and $7.0 \%$ of disability-adjusted life years caused by mental and substance use disorders, respectively. ${ }^{4}$ Severe mental illness (SMI) is a leading cause of disability, and the standard prevalent biomedical care model is neither an exclusive nor a comprehensive solution as it does not address the link between mental illness, stigma and poverty. ${ }^{5}$

While the literature on poverty, poor mental health $^{6}$ and disability ${ }^{7-9}$ is emerging, little has been done to examine the compounding associations between experienced stigma (unfair treatment or discrimination due to having a mental health issue), ${ }^{10}$ mental illness and poverty, especially in low-income countries. In high-income countries, ${ }^{11}$ income deprivation is identified as a major risk factor for persons with mental health issues, even for common mental disorders. ${ }^{12}$ Poor mental health linked to SMI has been associated with poverty during the recent economic crisis in middle-income and low-income countries, 
particularly India and China. ${ }^{13-15}$ People with mental disorders living in these countries are not only more likely to be poorer, but also unemployed and less educated. ${ }^{16}{ }^{17}$ Indisputably, a better understanding of the relationship between mental illness and poverty may yield useful knowledge to tailor public health interventions to complement biomedical treatment to improve outcomes.

Link and Phelan ${ }^{18}$ defined stigma as a process with five interrelated components: discrimination through a process of separation based on negative attitudes and prejudice resulting from labelling and cultural stereotypes of society towards the stigmatised group leading to social, economic and political power differences. Thornicroft $e t a l^{19}$ identify three elements of stigma: ignorance or misinformation, prejudice and discrimination.

Our paper focuses on the process of experienced discrimination as the manifestation of public stigma. ${ }^{20}$ The congruence of self-stigma and social exclusion may lead persons with SMIs (PSMIs) to face unfair treatment or discrimination and develop low self-esteem. ${ }^{21-24}$ Such stigma may prevent mentally ill persons from improving their conditions ${ }^{25}$ by creating a 'barrier to recovery' 26 and worsen their situation by pushing them into poverty through discriminatory practices. ${ }^{27-29}$

Stigma towards PSMI resulting in discrimination ${ }^{30} 31$ is persistent in India. ${ }^{32}$ Although the factors constituting poverty and discrimination linked to mental illness potentially can deprive persons of many resources, ${ }^{33} 34$ the dynamics of poverty, discrimination and mental health have not been fully addressed. The clinical literature argues that stigma is caused by mental illness and treating the latter biomedically will weaken the associated stigma. ${ }^{35}$ We argue instead that even treated PSMI are more likely to be multidimensionally poor due to discrimination resulting from stigma.

Many studies have focused on unidimensional effect of poverty on mental health, but have not explained how stigma towards mental illness can be an aggravating contributor to the intensity of poverty. We aimed to estimate the difference in incidence and intensity of poverty between PSMI and a comparable control group using a multidimensional poverty index (MPI) to explore deprivation in various dimensions of life. ${ }^{37}$ Going beyond traditional welfare economics approaches to poverty (ie, income or per capita expenditure), we explored nonmonetary dimensions of poverty such as education, health, quality of shelter, food intake and political participation. We assessed differences in intensity of poverty between PSMI and controls and explored how these differences vary as a function of discrimination resulting from stigma.

\section{METHODS}

Study design and setting

The primary objective was to assess differences in exposure to discrimination resulting from stigma and multidimensional poverty among cases compared with non-psychiatrically ill controls. Between November 2011 and June 2012, we carried out a case-control study based at the Department of Psychiatry of the Dr Ram Manohar Lohia (RML) Hospital in New Delhi (cases) and in the neighbourhood of residence of the cases (controls) to assess the impact of stigma associated to mental illness on poverty. The Department of Psychiatry at Dr RML hospital received respectively 10881 and 19528 new outpatients and 52389 and 45319 follow-ups of existing patients in 2012 and 2013. The department also has a 42-bed general psychiatry and de-addiction inpatient facility for men and women. It serves patients from the national Capital Region of Delhi.

\section{Participants}

We defined cases as outpatients diagnosed with schizophrenia or affective disorders by one of the 10 board-certified treating psychiatrists following International Classification of Diseases, 10th revision (ICD-10) criteria. ${ }^{38}$ Outpatients were informed about the study, and if they consented, were referred to researchers for written informed consent and evaluation with no further contact with those who refused. Transportation costs and a meal were provided to maximise recruitment and reduce selection bias.

We used a non-psychiatrically ill control group composed of randomly selected individuals matching the patients according to gender, age ( \pm 5 years) and neighbourhood of residence. Matched controls were selected by spinning a pointer at the door of the case's home and randomly selecting one household among 30 in the pointed direction. In this household, a person of same age and gender with no reported history of a mental health disorder was interviewed. It was not possible to conduct detailed interviews for diagnosis of all controls due to logistics as well as stigma of revealing mental illness. We excluded controls when unable to obtain consent. Only two case patients were not matched. Investigators together with the team manager contributed to sensitisation and awareness raising in the neighbourhoods of interest to maximise controls' participation rates. Consent for patients and controls adolescent between 13 and 18 was obtained by asking the parent or the legal guardian of the study subjects.

We conducted face-to-face interviews with all PSMI or a caregiver during hospital visits, and controls at home. We obtained information on demographics, socioeconomic factors, health conditions and accessibility to services, education, employment, income, livelihoods and social participation. The instrument was translated by experts into Hindi with iterative back-translation and tested in a pilot survey in October 2011. Investigators trained 2 experienced supervisors and 10 masters-level students over 2 weeks on survey concepts and goals, mental illness awareness, interview techniques followed by review, test and debriefing.

\section{Sample size}

To determine sample size, we used a matched design with a control to case ratio of 1 , the probability of 
exposure to poverty among controls of 0.22 and the correlation coefficient for exposure between matched cases and controls of $0.18 .{ }^{39}$ Considering the true OR for one dimension of poverty in exposed subjects relative to unexposed subjects as 2.2, we needed to enrol 205 case patients to be able to reject the null hypothesis that this OR equals 1 with probability of 0.9 . The type 1 error probability associated with this test of this null hypothesis is 0.05 . We enrolled 649 case patients to allow for subgroup analyses including impact on poverty of discrimination stratified by gender, age and caste.

\section{Efforts to minimise bias}

New patients were first interviewed by a junior psychiatrist who made a provisional diagnosis and discussed details with a board-certified psychiatrist who then diagnosed and managed the case. To minimise diagnosis bias, we trained all psychiatrists on the ICD-10 criteria. Information bias was minimised by reviewing the questionnaire about exposure to poverty to ensure accuracy, completeness and content validity with experts and by testing it with a sample group of patients and families. Investigators revised the content for relevance to poverty in order to maximise item appropriateness. They first defined the concept of multidimensional poverty and reviewed the empirical and theoretical literature to identify the right deprivation items to include in the instrument they were developing. They then checked whether the questions covered all dimensions of the concept of multidimensional poverty and whether the phrasing respectively in English and Hindi was accurately reflecting the underlying concept of deprivation we were looking for in each dimension. Two experts familiar with multidimensional poverty reviewed the initial list of items and made suggestions about adding items that were omitted. We then organised a focus group discussion (FGD) with seven experts, psychiatrists, psychologists and social workers from Dr RML hospital to establish whether the 17 domains of poverty selected were adapted and relevant for the context of New Delhi and were providing a comprehensive overview of the concept. They also ranked these domains by order of importance of deprivation. A similar focus group was organised with eight hospital outpatients with SMI. We finally tested the poverty questionnaire with a group of 20 outpatients at the Department of Psychiatry at Dr RML hospital. We prompted them with questions to check for their understanding of poverty to identify the language they used to explain the notion of poverty, as well as to ascertain their understanding of the questions in order to make sure the instrument's purpose made sense to them. Finally, two other experts revised the final version to make sure items illustrate the content of multidimensional poverty. ${ }^{40}$

We also carried out test-retest to test for recall bias and social desirability bias. Interviews with 71 respondents (both cases and controls) for test-retest reliability were carried out on two occasions with a gap of $10-15$ days by the same enumerator to check to what degree a given respondent provided same responses for the poverty items. We compared the scores between the two sets of responses. Results show overall acceptable level of reliability (over 0.7 for interclass correlation) for the different poverty variables.

\section{Quantitative variables}

We selected 17 indicators of deprivation reflecting aspects of well-being (table 1) identified by literature review and validated through FGDs with experts and PSMI/caregivers. Both groups identified and agreed on deprivation cut-offs for each indicator through participatory deliberation. ${ }^{41}$ Some standard dimensions were not included due to lack of relevance in Delhi. For instance, few respondents lacked access to diet staples. ${ }^{1}$

We classified the selected indicators in three major domains of deprivation: individual-level capabilities, household-level material well-being and individual-level psychosocial factors. The first domain was composed of nine indicators. Access to secondary school was the indicator for education; dropping out before reaching secondary school was the cut-off. Unemployment was a major source of vulnerability; deprivation of work was the cut-off. Food security was measured by access to three meals per day, and respondents eating less were considered deprived. Following the Unicef definitions, improved indoor air quality using cooking gas, improved drinking water by pipe into residence and improved sanitation by private flush toilet defined absence of deprivation for indicators 6-8. Finally, individual income constituted a monetary indicator.

Material well-being of the household was composed of two series of indicators. Three indicators outlined conditions of living: minimum space per person (deprivation threshold of 40 square feet per person); home ownership (renting was the cut-off); and poor quality housing was having either the flooring, walls or roof made of Kutcha (precarious or temporary) material. Material wealth was defined by three complementary indicators: the household average per capita income (threshold at the international poverty line of US $\$ 1.25$ per day or 68 Indian rupees) $;{ }^{42}$ assets included typical goods owned by the household; ${ }^{2}$ and monthly household expenditures. ${ }^{3}$

Finally, two psychosocial indicators were selected: physical safety, measured through an indicator of perception of unsafe environment, and political participation in the municipal elections.

\footnotetext{
${ }^{1}$ For vegan individuals, the diet staple included at least dal on a daily basis; for non-vegan individuals, it included dairy products on a daily basis. Meat for non-vegetarian individuals was not considered as a diet requirement and therefore deprivation of meat is not an indicator of poor diet.

${ }^{2}$ Assets include landline, mobile phones, wooden/steel sleeping cot, mattress, table, clock/watch, charpoy, refrigerator, radio/transistor electric fan, television, bicycle, computer, moped/scooter/motorcycle, car.

${ }^{3}$ Expenditures include food, health, school, transportation, savings and personal care products.
} 
Table 1 Dimensions, indicators and cut-off of deprivation

\begin{tabular}{|c|c|c|c|}
\hline Dimensions & Indicators & Questions & Cut-off \\
\hline \multirow{9}{*}{$\begin{array}{l}\text { Individual-level basic } \\
\text { capabilities }\end{array}$} & Health access & Could you receive healthcare when sick? & Deprived of healthcare \\
\hline & Education & What is your level of education? & $\begin{array}{l}\text { Primary education } \\
\text { completed }\end{array}$ \\
\hline & $\begin{array}{l}\text { Access to } \\
\text { employment }\end{array}$ & What is your usual primary activity? & Not working \\
\hline & Food security & $\begin{array}{l}\text { How many meals are usually served in your } \\
\text { household in a day? }\end{array}$ & 1 or 2 meals \\
\hline & $\begin{array}{l}\text { Source of } \\
\text { drinking water }\end{array}$ & What is the primary source of drinking water? & $\begin{array}{l}\text { Pipe outside home/public } \\
\text { pump } \\
\text { tanker truck/cart with small } \\
\text { tank } \\
\text { water from a covered well } \\
\text { unprotected well } \\
\text { spring/river/dam/lake/pond/ } \\
\text { stream }\end{array}$ \\
\hline & Indoor air quality & What is the primary source of cooking fuel? & $\begin{array}{l}\text { Wood, coal/charcoal, dung } \\
\text { kerosene, straw/shrubs/ } \\
\text { grass/crop }\end{array}$ \\
\hline & Type of sanitation & $\begin{array}{l}\text { What type of toilet facilities do you use when at } \\
\text { home? }\end{array}$ & $\begin{array}{l}\text { Open field, pit latrine } \\
\text { improved ventilated pit } \\
\text { public latrine }\end{array}$ \\
\hline & Type of lighting & What is your primary source of lighting? & $\begin{array}{l}\text { Generator, kerosene lamp, } \\
\text { petromax, candle, none }\end{array}$ \\
\hline & Individual income & What is your income? & Less than $\$ 1.25$ per day \\
\hline \multirow[t]{6}{*}{$\begin{array}{l}\text { Household-level } \\
\text { material well-being }\end{array}$} & Crowded space & How many people live in the dwelling? & $\begin{array}{l}\text { Less than } 50 \text { square feet } \\
\text { per person }\end{array}$ \\
\hline & $\begin{array}{l}\text { Housing } \\
\text { ownership }\end{array}$ & Does the family own the house? & Do not own the house \\
\hline & Housing quality & $\begin{array}{l}\text { Are the material used for walls, floor and roof in } \\
\text { your house kutcha or pucca? }\end{array}$ & $\begin{array}{l}\text { Any of walls, floor or roof is } \\
\text { kutcha }\end{array}$ \\
\hline & Assets ownership & $\begin{array}{l}\text { Do you possess any of the following? Mobile } \\
\text { phone, landline, wooden/steel sleeping cot, } \\
\text { mattress, table, clock/watch, charpoy, refrigerator, } \\
\text { radio/transistor, electric fan, television, bicycle, } \\
\text { computer, moped/scooter/motorcycle, car }\end{array}$ & Lowest two asset quintiles \\
\hline & $\begin{array}{l}\text { Household per } \\
\text { capita income }\end{array}$ & What is the family income? & $\begin{array}{l}\text { Less than } \$ 1.25 \text { per capita } \\
\text { per day }\end{array}$ \\
\hline & $\begin{array}{l}\text { Household } \\
\text { expenditures }\end{array}$ & What is the household's monthly expenditure? & $\begin{array}{l}\text { Less than } \$ 1.25 \text { per capita } \\
\text { per day }\end{array}$ \\
\hline \multirow{2}{*}{$\begin{array}{l}\text { Individual-level } \\
\text { psychosocial } \\
\text { dimensions }\end{array}$} & Physical safety & How safe is the place where you live? & Rather or very unsafe \\
\hline & $\begin{array}{l}\text { Political } \\
\text { participation }\end{array}$ & Did you vote in the last municipal election? & Did not vote \\
\hline
\end{tabular}

Studies in India have shown that stigma resulting in discriminatory practices is perceived to be high in the family and the community. ${ }^{43}{ }^{44}$ As a result, we measured experienced discrimination as a dimension of stigma through self-evaluation of unfair treatment by the family. We asked all respondents whether they were excluded from family decision compared with other household members of the same generation. Unfair treatment within family is a feature of stigma in India. ${ }^{44}$ We tested this through FGDs with PSMI of both genders. We found high association between SMI and exclusion from regular family decisions, particularly for women.
Other dimensions of participation did not show any discriminatory process. Inclusion in community activities showed similar 30\% levels of participation between PSMI and controls. A possible explanation for participation is that where symptoms of mental illness are managed by treatment family develop coping strategies through symbolic social participation and selective disclosure to avoid rejection, stigma and avoidance by others associated with their relative's condition. ${ }^{45-47}$ Finally, we enquired about participation in political activities such as 'gram sabhas' or local associations. We found generalised low participation in political activities, 
which is a common feature in New Delhi and therefore not a good indicator of experienced discrimination.

\section{Statistical analysis}

Our primary aim was to explore the effect of mental illness and stigma on poverty. We used an unmatched MPI measure to identify differences in levels of poverty between PSMI and controls. ${ }^{37}$ Dimensions were independently assessed and the method focused on dimensional shortfalls. This method allowed us to aggregate dimensions of multidimensional poverty measures and consisted of two different forms of cut-offs: one for each dimension and the other relating to cross-cutting dimensions. If an individual fell below the chosen cut-off on a particular dimension, he/she was identified as deprived. The second poverty cut-off determined the number of dimensions in which a person must be deprived to be deemed multidimensionally poor.

We first performed one-way analyses to assess differences in poverty levels and discrimination between PSMI and controls, by gender and caste adjusting for post hoc pairwise comparisons using the Scheffe method. We also carried out correlation analysis to assess overlap of dimensions of deprivation.

We then calculated three indicators of multidimensional poverty: (i) the headcount ratio $(\mathrm{H})$, indicating how many people fall below each deprivation cut-off; (ii) the average poverty gap (A), denoting the average number of deprivations each person experiences; and (iii) the adjusted headcount (M0), which is the headcount ratio $(\mathrm{H})$ by the average poverty gap $(\mathrm{A})$ and indicates the breadth of poverty. We established the contribution of each dimension of poverty for cases and controls by dividing each of the two subgroups' poverty level by the overall poverty level, multiplied by the population portion of each subgroup.

To assess potential bias in our estimates of MPI, we carried out sensitivity analysis and compared three measures of poverty with: (i) equal weight for every indicator in each dimension, (ii) individual rankings of indicators done by experts at Dr RML hospital during FGDs transformed into individual weights and then taking the average of the individual weights, ${ }^{48}$ and (iii) group ranking based on the mean of individual rankings of indicators during FGDs and taking the weight according to the group ranking. ${ }^{49}$ We found consistency across measures (data not shown).

We finally calculated the crude and adjusted ORs with associated $95 \%$ CIs using a logistic regression model to identify association between stigma, SMI and multidimensional poverty. We used 'no participation' as the reference category. We defined a binary outcome for poverty (poor/ non-poor) using the adjusted headcount ratio (M0) for a cut-off $\mathrm{k}=6$ corresponding to the highest gap between PSMI and controls. This cut-off corresponds to a prevalence of poverty of $30.7 \%$ above the recent estimates of $13.7 \%$ of urban Indians below the poverty line fixed at 28.65 Indian rupees by the Indian Planning Commission, ${ }^{50}$ which has been criticised for being unrealistic. This cut-off is in line with World Bank recent estimate that $33 \%$ of India's population lives below the international poverty line established at $\$ 1.25$ per capita per day. ${ }^{51} \mathrm{We}$ characterised how SMI results in higher intensity of multidimensional poverty due to stigma. Aware that stigma and discrimination may also affect women ${ }^{52}$ and members of lower castes, ${ }^{53}$ we adjusted the model for potential confounders significantly associated with poverty and family discrimination: caste (in case of difference within the family), gender and age. We carried out sensitivity analysis for different values of the cut-off $k$ and found robustness in our model (data not shown). For all analyses, a $p$ value of $<0.05$ was considered significant. Missing values were treated as being missing completely at random. We used Stata (V.12.0) for database processing and all analysis.

\section{RESULTS}

\section{Participants}

We interviewed 649 case patients and 647 controls. Of these, we excluded $110(17 \%)$ cases and 151 (23\%) controls, respectively, who did not complete the interview or for whom the data were incomplete. The final analysis included 537 cases and 496 controls (figure 1). The

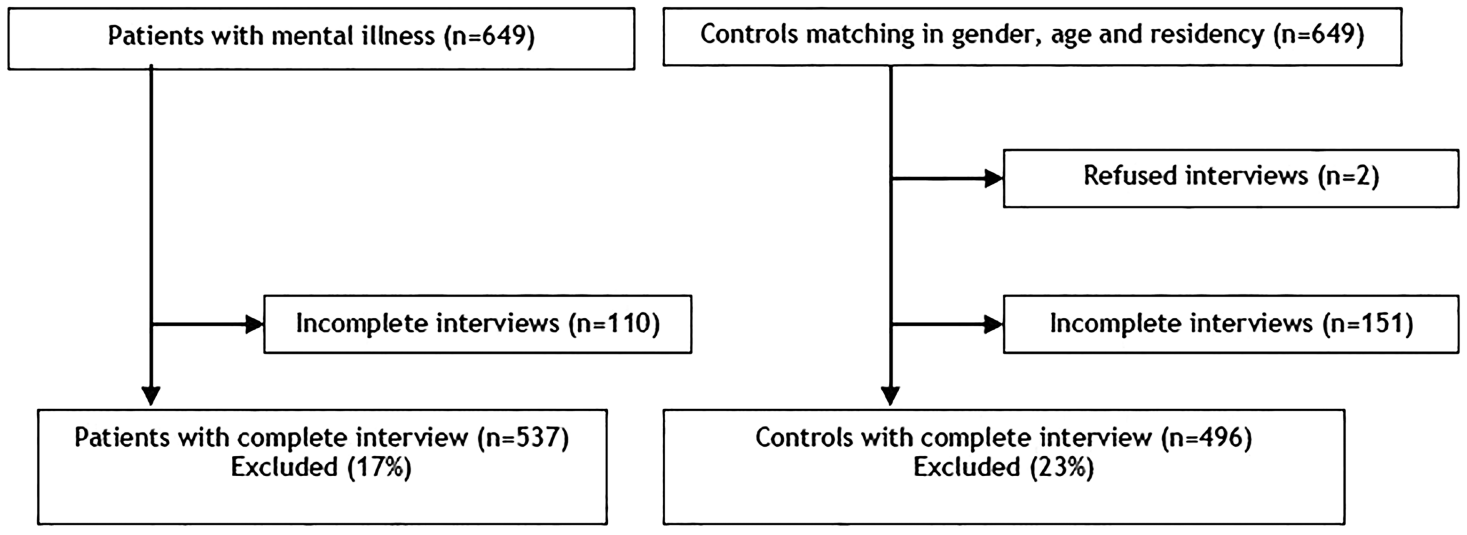

Figure 1 Flow chart depicting enrolment of patients with mental illness and controls without mental illness. 
Table 2 Characteristics of poverty and discrimination comparing patients and controls and by gender and caste

\begin{tabular}{|c|c|c|c|c|c|c|c|c|c|c|c|c|c|c|c|}
\hline Dimension & $\begin{array}{l}\text { PSMI } \\
(n=647)\end{array}$ & $\begin{array}{l}\text { Control } \\
(n=649)\end{array}$ & p Value & $\begin{array}{l}\text { Male } \\
\text { PSMI } \\
(n=411)\end{array}$ & $\begin{array}{l}\text { Male } \\
\text { controls } \\
(n=408)\end{array}$ & p Value & $\begin{array}{l}\text { Other } \\
\text { castes } \\
\text { PSMI }\end{array}$ & $\begin{array}{l}\text { Other } \\
\text { castes } \\
\text { controls }\end{array}$ & p Value & $\begin{array}{l}\text { Female } \\
\text { PSMI } \\
(n=238)\end{array}$ & $\begin{array}{l}\text { Female } \\
\text { controls } \\
(n=238)\end{array}$ & p Value & $\begin{array}{l}\text { ST/SC/ } \\
\text { OBC } \\
\text { PSMI }\end{array}$ & $\begin{array}{l}\text { ST/SCI } \\
\text { OBC } \\
\text { controls }\end{array}$ & p Value \\
\hline Health access & $26(4.0)$ & $16(2.9)$ & 0.281 & $13(3.2)$ & $4(1.0)$ & 0.802 & $17(4.8)$ & $10(2.5)$ & 0.630 & $13(5.5)$ & $12(5.0)$ & 1.0 & 9 (3.3) & $6(2.5)$ & 0.995 \\
\hline Education & 155 (23.9) & $129(19.9)$ & 0.086 & $70(17.0)$ & $52(12.8)$ & 0.511 & $61(17.3)$ & 59 (14.9) & 0.879 & $85(35.7)$ & 77 (32.4) & 0.843 & $82(29.9)$ & $65(26.8)$ & 0.850 \\
\hline Employment & $396(61.0)$ & $252(39.0)$ & $<0.0001$ & $188(45.7)$ & 68 (16.7) & $<0.0001$ & $222(63.1)$ & 151 (38.1) & $<0.0001$ & $208(87.4)$ & $184(77.3)$ & $<0.0001$ & $164(59.9)$ & 96 (39.5) & $<0.0001$ \\
\hline Food security & 343 (52.9) & $250(38.6)$ & 0.103 & $213(51.8)$ & $155(38.0)$ & 0.789 & 165 (46.9) & 133 (33.6) & 0.413 & $130(54.6)$ & 95 (39.9) & 0.613 & $163(59.5)$ & $113(46.5)$ & 0.964 \\
\hline Source of water & $122(18.8)$ & 118 (18.2) & 0.724 & $86(20.9)$ & $74(18.1)$ & 0.732 & 62 (17.6) & $61(15.40)$ & 0.881 & $36(15.1)$ & 44 (18.5) & 0.837 & $55(20.1)$ & $56(23.1)$ & 0.893 \\
\hline Indoor air quality & $48(7.4)$ & $38(5.9)$ & 0.271 & $35(8.5)$ & $24(5.9)$ & 0.515 & $17(4.8)$ & $13(3.3)$ & 0.861 & $13(5.4)$ & $14(5.9)$ & 0.998 & $27(9.9)$ & $24(9.9)$ & 1.0 \\
\hline $\begin{array}{l}\text { Type of } \\
\text { sanitation }\end{array}$ & $215(33.1)$ & $180(27.8)$ & 0.040 & $147(35.8)$ & $60(25.2)$ & 0.271 & $93(26.4)$ & $104(26.3)$ & 1.0 & $68(28.6)$ & $66.7(29.4)$ & 0.897 & $112(40.9)$ & $72(29.6)$ & 0.050 \\
\hline Type of lighting & $7(1.1)$ & $10(1.6)$ & 0.458 & $4(1.0)$ & $8(2.0)$ & 0.674 & $0(0)$ & $4(1.0)$ & 0.675 & $3(1.3)$ & $2(0.8)$ & 0.984 & $6(2.2)$ & $6(2.5)$ & 0.994 \\
\hline $\begin{array}{l}\text { Individual } \\
\text { income }\end{array}$ & $369(68.7)$ & 238 (47.9) & $<0.0001$ & 176 (53.3) & 74 (24.3) & $<0.0001$ & 199 (68.9) & $138(45.5)$ & 0.932 & 193 (93.2) & $164(85.9)$ & $<0.0001$ & $154(68.1)$ & 95 (52.8) & 0.241 \\
\hline Crowded space & $206(31.7)$ & $164(25.4)$ & 0.010 & $130(32.0)$ & 94 (23.3) & 0.059 & 89 (25.3) & $70(17.7)$ & 0.131 & 76 (32.3) & 70 (29.7) & 0.938 & $104(38.0)$ & $91(37.5)$ & 0.999 \\
\hline $\begin{array}{l}\text { Housing } \\
\text { ownership }\end{array}$ & $223(41.5)$ & $148(29.8)$ & $<0.0001$ & $160(39.7)$ & 119 (29.2) & 0.028 & $152(43.2)$ & 75 (30.9) & 0.002 & $99(42.1)$ & 78 (32.7) & 0.264 & 99 (36.2) & $119(30.1)$ & 0.667 \\
\hline Housing quality & $39(6.3)$ & $13(2.2)$ & $<0.0001$ & $29(7.1)$ & $7(1.67)$ & 0.001 & $13(3.7)$ & $6(1.5)$ & 0.493 & $10(4.2)$ & $6(2.5)$ & 0.830 & $23(8.4)$ & $7(2.9)$ & 0.007 \\
\hline $\begin{array}{l}\text { Assets } \\
\text { ownership }\end{array}$ & $294(45.3)$ & $214(33.1)$ & $<0.0001$ & 201 (48.9) & $125(30.6)$ & $<0.0001$ & $131(37.2)$ & $94(23.7)$ & 0.002 & $93(39.1)$ & 89 (37.4) & 0.986 & $148(54.0)$ & $116(47.7)$ & 0.531 \\
\hline $\begin{array}{l}\text { Household } \\
\text { income }\end{array}$ & $287(44.2)$ & $239(36.9)$ & 0.002 & $176(42.8)$ & $142(34.8)$ & 0.082 & $132(37.5)$ & $116(29.3)$ & 0.096 & 111 (46.6) & $97(40.8)$ & 0.553 & 141 (51.5) & $119(49.0)$ & 0.907 \\
\hline $\begin{array}{l}\text { Household } \\
\text { expenditures }\end{array}$ & 373 (57.5) & $393(60.7)$ & 0.978 & $238(58.0)$ & $239(58.6)$ & 0.799 & $180(51.1)$ & $209(52.8)$ & 0.947 & $135(56.7)$ & $154(64.7)$ & 0.571 & $178(65.0)$ & $180(74.0)$ & 0.4291 \\
\hline Physical safety & $117(18.0)$ & $134(20.7)$ & 0.221 & $80(19.6)$ & $80(19.6)$ & 0.907 & $51(14.5)$ & 68 (17.2) & 1.0 & 53 (22.3) & $53(22.3)$ & 0.824 & 62 (22.6) & 65 (26.8) & 1.0 \\
\hline $\begin{array}{l}\text { Political } \\
\text { participation }\end{array}$ & $265(40.8)$ & 209 (32.3) & 0.001 & 163 (39.7) & $122(29.9)$ & 0.030 & $152(43.2)$ & 125 (31.6) & 0.005 & 102 (42.9) & $86(36.1)$ & 0.506 & $102(37.2)$ & 80 (32.9) & 0.760 \\
\hline $\begin{array}{l}\text { Discrimination in } \\
\text { family decisions }\end{array}$ & $178(27.4)$ & $116(17.9)$ & $<0.0001$ & $71(17.3)$ & $12(2.9)$ & $<0.0001$ & $92(26.1)$ & 71 (17.9) & 0.042 & $107(45.0)$ & $104(43.7)$ & 0.988 & 78 (28.5) & $43(17.7)$ & 0.020 \\
\hline
\end{tabular}


distribution between cases and controls was similar for gender (305 and 330 men, respectively, $61.5 \%$ in both cases) and age (15-74 and 13-74 and median 35 and 36 , respectively).

Table 2 reports the headcount ratios $(\mathrm{H})$ or incidence of deprivation in each dimension. There were statistically significantly higher numbers of deprived PSMI than controls in nine dimensions. Differences were very high for access to employment (28.1\% difference), individual income $(20.7 \%)$ and relatively high for food security $(15.1 \%)$ and house ownership $(11.7 \%)$. In only one dimension-perception of physical safety-was there a reverse non-significant difference as the number of controls was higher than the number of PSMI.

Table 2 also show results by gender and caste. Compared with male PSMI, the proportion of deprived female PSMI was significantly higher (10 of 17 dimensions). Similarly, a higher number of PSMI (vs controls) from 'scheduled castes' (SC), 'scheduled tribes' (ST) or 'other backward castes' (OBC) were poorer on 13 (vs 16 dimensions) compared with PSMI (vs controls) from unreserved castes.

To investigate possible overlap of dimensions of poverty, we calculated the estimates for the Spearman's rank correlation coefficients between each pair of dimensions of deprivation (table 3 ). We found no evidence of strong correlation between dimensions, illustrating absence of association except for household income and expenditures. We nevertheless kept both indicators to calculate MPI to account for information bias (particularly recall bias) often associated with measures of income in household surveys. ${ }^{54}{ }^{55}$ Significantly, this result demonstrates that a unique welfare indicator of poverty such as income cannot represent all aspects of deprivation.

\section{Multidimensional poverty}

Results in table 4 report the multidimensional headcount ratio $(\mathrm{H})$, the average deprivation shared across the poor (A) and the adjusted headcount ratio (M0) for all possible cut-offs and for the two groups. Depending on the chosen cut-off, the proportion of PSMI and controls who were multidimensionally poor varied greatly. For a cut-off of 1, 97.2\% of PSMI and 91.7\% of controls were deprived: taking a union approach of deprivation in one dimension, this translates into quasi-universal poverty. On average, PSMI were deprived on 5 dimensions and controls on 3.9. If multidimensional poverty requires deprivation in four, five or six dimensions simultaneously, the proportion of poor PSMI (compared with poor controls) becomes $68.5 \%$ (compared with $48.6 \%$ ), $51.6 \%$ $(35.9 \%)$ or $38.5 \%(22.2 \%)$. Conversely, if we adopt the intersection approach where being poor implies being deprived in all 17 dimensions, nobody in the sample is poor and $<1 \%$ of the sample is deprived in 13 .

The adjusted headcount ratio (M0) shows that PSMI were worse off than controls for a cut-off $(k)$ value between 1 and 12 dimensions. This difference is significant $(\mathrm{p}<0.001)$ for $(\mathrm{k})=1$ to $(\mathrm{k})=10$ dimensions and

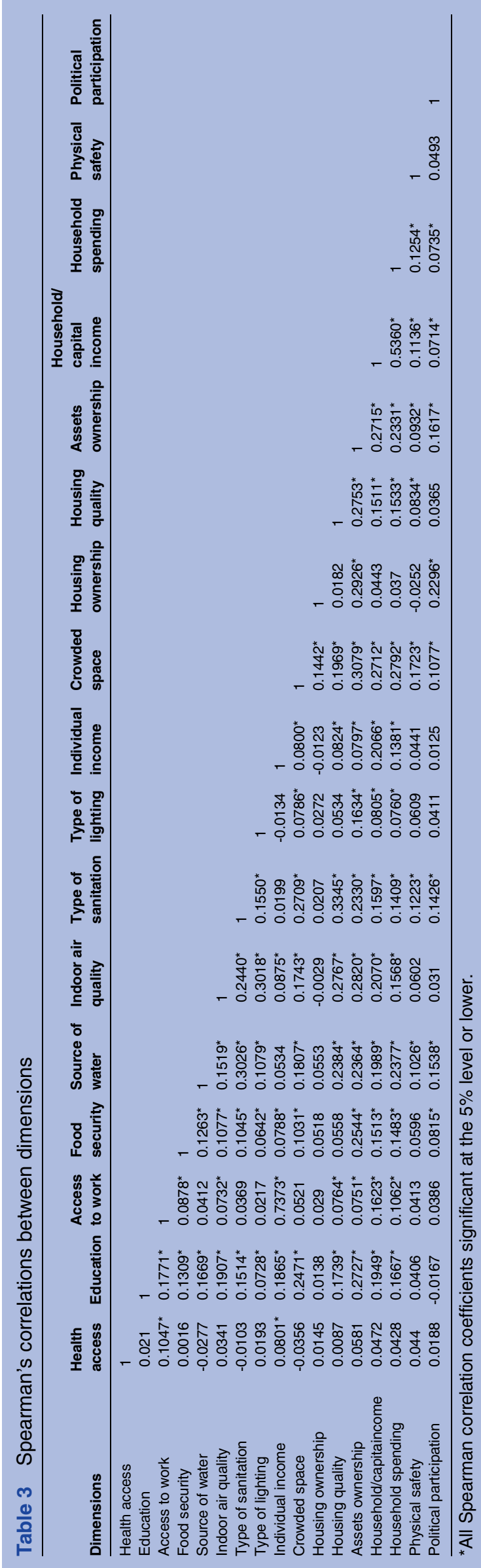


Table 4 Multidimensional poverty measures for persons with severe mental illness (PSMI) and controls and by gender and caste

\begin{tabular}{|c|c|c|c|c|c|c|c|c|c|c|c|}
\hline \multirow[b]{2}{*}{ Cut-off k } & \multicolumn{3}{|l|}{ All } & \multicolumn{3}{|l|}{ PSMI } & \multicolumn{3}{|c|}{ Controls } & \multirow[b]{2}{*}{ T-value for $\mathrm{M} 0 \ddagger$} & \multirow{2}{*}{$\begin{array}{l}\text { \% difference } \\
\text { in } \mathrm{MO}^{*}\end{array}$} \\
\hline & $\overline{\mathrm{H} \dagger}$ & A & MO & $\overline{\mathbf{H}}$ & A & MO & $\overline{\mathbf{H}}$ & A & MO & & \\
\hline 1 & 0.946 & 0.276 & 0.261 & 0.972 & 0.302 & 0.293 & 0.917 & 0.247 & 0.227 & -6.574 & 29.3 \\
\hline 2 & 0.849 & 0.301 & 0.256 & 0.901 & 0.321 & 0.289 & 0.792 & 0.277 & 0.219 & -6.583 & 31.7 \\
\hline 3 & 0.739 & 0.328 & 0.243 & 0.834 & 0.337 & 0.281 & 0.635 & 0.316 & 0.201 & -7.051 & 39.9 \\
\hline 4 & 0.590 & 0.367 & 0.216 & 0.685 & 0.372 & 0.255 & 0.486 & 0.359 & 0.175 & -6.378 & 46.0 \\
\hline 5 & 0.440 & 0.411 & 0.181 & 0.516 & 0.417 & 0.215 & 0.359 & 0.403 & 0.145 & -5.210 & 48.5 \\
\hline 6 & 0.307 & 0.462 & 0.142 & 0.385 & 0.458 & 0.177 & 0.222 & 0.471 & 0.104 & -5.297 & 69.2 \\
\hline 7 & 0.224 & 0.503 & 0.113 & 0.277 & 0.499 & 0.138 & 0.165 & 0.511 & 0.084 & -4.062 & 64.0 \\
\hline 8 & 0.144 & 0.553 & 0.080 & 0.175 & 0.550 & 0.096 & 0.111 & 0.559 & 0.062 & -2.791 & 55.2 \\
\hline 9 & 0.090 & 0.603 & 0.054 & 0.112 & 0.595 & 0.066 & 0.067 & 0.619 & 0.041 & -2.334 & 61.6 \\
\hline 10 & 0.055 & 0.650 & 0.036 & 0.069 & 0.636 & 0.044 & 0.040 & 0.676 & 0.027 & -1.776 & 60.6 \\
\hline
\end{tabular}

\begin{tabular}{|c|c|c|c|c|c|c|c|c|c|c|}
\hline \multirow[b]{2}{*}{ Cut-off k } & \multicolumn{2}{|l|}{ PSMI } & \multicolumn{2}{|c|}{ Controls } & \multirow{2}{*}{$\begin{array}{l}\text { T-value } \\
\text { for M0 }\end{array}$} & \multicolumn{2}{|l|}{ PSMI } & \multicolumn{2}{|c|}{ Controls } & \multirow{2}{*}{$\begin{array}{l}\text { T-value } \\
\text { for M0 }\end{array}$} \\
\hline & $\overline{\mathbf{H}}$ & MO & $\overline{\mathbf{H}}$ & MO & & $\overline{\mathbf{H}}$ & MO & $\overline{\mathbf{H}}$ & MO & \\
\hline & Female & & & & & Male & & & & \\
\hline 1 & 0.990 & 0.327 & 0.917 & 0.227 & -2.237 & 0.961 & 0.272 & 0.879 & 0.185 & -6.797 \\
\hline 2 & 0.981 & 0.327 & 0.792 & 0.219 & -2.322 & 0.852 & 0.265 & 0.702 & 0.175 & -6.717 \\
\hline 3 & 0.942 & 0.322 & 0.635 & 0.201 & -2.585 & 0.767 & 0.255 & 0.508 & 0.152 & -7.140 \\
\hline 4 & 0.783 & 0.294 & 0.486 & 0.175 & -2.157 & 0.624 & 0.230 & 0.364 & 0.127 & -6.652 \\
\hline 5 & 0.628 & 0.257 & 0.359 & 0.145 & -1.947 & 0.445 & 0.188 & 0.256 & 0.101 & -5.323 \\
\hline 6 & 0.473 & 0.212 & 0.222 & 0.104 & -2.191 & 0.330 & 0.154 & 0.148 & 0.069 & -5.263 \\
\hline 7 & 0.343 & 0.166 & 0.165 & 0.084 & -1.415 & 0.236 & 0.121 & 0.105 & 0.054 & -4.302 \\
\hline 8 & 0.184 & 0.100 & 0.111 & 0.062 & -0.396 & 0.170 & 0.094 & 0.079 & 0.043 & -3.438 \\
\hline 9 & 0.116 & 0.068 & 0.067 & 0.041 & -0.458 & 0.109 & 0.065 & 0.049 & 0.030 & -2.752 \\
\hline \multirow[t]{2}{*}{10} & 0.068 & 0.043 & 0.040 & 0.027 & -0.157 & 0.070 & 0.044 & 0.030 & 0.019 & -2.266 \\
\hline & \multicolumn{5}{|c|}{ SC/ST/OBC } & \multicolumn{4}{|c|}{ Other castes } & \\
\hline 1 & 0.987 & 0.320 & 0.972 & 0.280 & -2.437 & 0.958 & 0.264 & 0.884 & 0.194 & -5.532 \\
\hline 2 & 0.942 & 0.317 & 0.900 & 0.276 & -2.458 & 0.862 & 0.258 & 0.723 & 0.185 & -5.510 \\
\hline 3 & 0.863 & 0.308 & 0.783 & 0.262 & -2.496 & 0.799 & 0.251 & 0.545 & 0.164 & -6.097 \\
\hline 4 & 0.748 & 0.288 & 0.628 & 0.235 & -2.574 & 0.623 & 0.220 & 0.396 & 0.137 & -5.246 \\
\hline 5 & 0.606 & 0.254 & 0.494 & 0.203 & -2.262 & 0.426 & 0.174 & 0.274 & 0.109 & -3.927 \\
\hline 6 & 0.460 & 0.211 & 0.306 & 0.148 & -2.680 & 0.304 & 0.138 & 0.162 & 0.076 & -3.843 \\
\hline 7 & 0.336 & 0.168 & 0.233 & 0.122 & -1.917 & 0.215 & 0.106 & 0.125 & 0.063 & -2.788 \\
\hline 8 & 0.217 & 0.118 & 0.161 & 0.092 & -1.160 & 0.131 & 0.072 & 0.086 & 0.047 & -1.809 \\
\hline 9 & 0.133 & 0.079 & 0.100 & 0.064 & -0.757 & 0.090 & 0.053 & 0.050 & 0.030 & -1.864 \\
\hline 10 & 0.075 & 0.048 & 0.061 & 0.043 & -0.308 & 0.055 & 0.034 & 0.030 & 0.019 & -1.459 \\
\hline
\end{tabular}

Rows $11-17$ are omitted as very few are deprived in $>10$ dimensions, no one is deprived in $>15$ dimensions.

$\mathrm{HH}$ is the percentage of the population that is poor $\mathrm{H}={ }^{*}\left(\mathrm{MO}_{\mathrm{PSMI}} \mathrm{M0_{ \text {controls } }}\right) / \mathrm{MO} \mathrm{PSMI}_{\mathrm{PS}}$.

$\ddagger$ Adjusted Wald test for difference in adjusted headcount ratio between patients and controls. The average poverty gap ( $A$ ) is not presented for gender and caste but can be easily calculated dividing the adjusted headcount (MO) by the headcount ratio ( $\mathrm{H})$.

highest $(69 \%$ difference) for $(k)=6$. The average deprivation share (A) is higher among PSMI for a value of $(\mathrm{k})$ between 1 and 5 and highest for $(k)=1 \quad(22 \%$ difference). For a (k) between 6 and 14, the total number of deprivations faced by poor PSMI is slightly lower on average than for controls. Less than $30 \%$ of people were poor in six dimensions or more, and the difference between PSMI and controls was the highest for a (k) value of $14(7 \%)$.

To further investigate the association between poverty and mental illness, analysis was repeated for all possible cut-offs and for gender and caste (table 4). Multidimensional poverty was significantly higher for female PSMI compared with female controls for any threshold between one and seven dimensions $(p<0.001)$ but also for male PSMI for any threshold between one and nine dimensions. On average, $62.8 \%$ of female PSMI were deprived on five dimensions or more compared with $35.9 \%$ of female controls, $44.5 \%$ of male PSMI and $25.6 \%$ of male controls. For female PSMI and controls-and male PSMI and controls, respectively-the difference is particularly pronounced and significant for highest cut-off values, and maximum for six and seven dimensions, respectively. The adjusted headcount ratio (M0) shows that SC/ ST/OBC PSMI are worse off regardless of the value of (k) 1 through 10 than SC/ST/OBC controls and other caste PSMI or controls. (M0) for SC/ST/OBC controls is higher than for other caste PSMI for all $(\mathrm{k})$ values. 


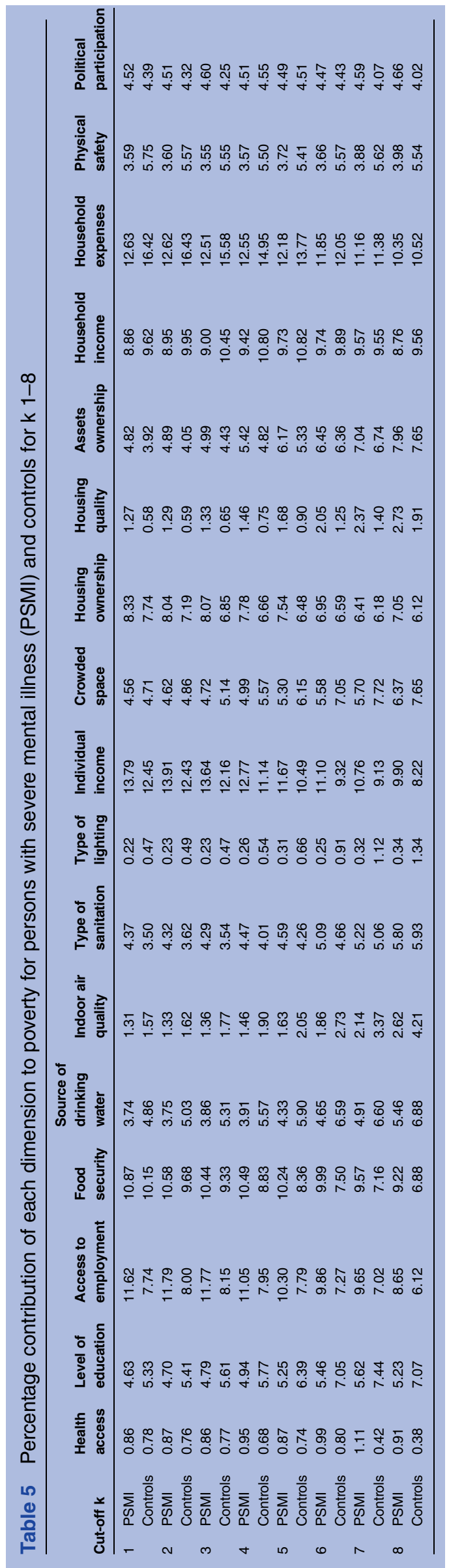

Table 5 presents the percentage contribution of each dimension to (M0) for different (k). Deprivations in individual income household expenditures and employment were contributing each $>10 \%$ to the overall (M0) for PSMI, whatever the value (k) between 1 and 8 . For controls, employment was a less salient contributor while the contribution from household income was among the highest.

\section{Poverty and stigma}

Association between multidimensional poverty and stigma was strong even when controlling for SMI, gender, caste and age (table 6 ; all $\mathrm{p}<0.0001)$. We included interaction of stigma, SMI with caste and found that this term was strongly and positively associated with a high level of poverty: the $\mathrm{OR}$ of being multidimensionally poor for PSMI from SC/ST/OBC compared with controls from unreserved castes was 7.36 (95\% CI 3.94 to 13.7). Similarly, we allowed for differential gender effects by including interaction of stigma and SMI with the gender of the respondent and found high effect on poverty: female PSMI were 9.61 (95\% CI 5.58 to 16.5 ) more likely to be poor compared with male controls.

\section{DISCUSSION}

Our findings establish that intensity of multidimensional poverty is higher for PSMI than the rest of the population. They also indicate that it is higher for women with SMI and for SC/ST/OBC with SMI. Deprivation of employment and income appear to be major contributing factors to MPI. Lack of employment and income appears to aggravate mental illness. Finally, our findings suggest that stigma linked to SMI, compounded with others (particularly SC/ST/OBC and women), negatively impact poverty.

The congruence of SMI and poverty, in a context of high prejudice against mental illness, compromises improvement. Mental illness in India is linked to lack of knowledge and pervasive negative assumptions, the most common being that PSMI are violent and unable to work. ${ }^{18} 3144$ Not surprisingly, deprivation of employment and income contributes highly to multidimensional poverty of PSMI compared with controls. This finding ties in with a study on employment for Indian men with schizophrenia, which found that employment provided not just an essential social role but was also a condition for rehabilitation, enhanced confidence and self-esteem. ${ }^{44}$

Although there is evidence of differences in mental health outcomes between men and women, analyses of gender disparities are lacking in literature on poverty and mental health in low-income countries. ${ }^{44} 5657$ In our sample, women with SMI were systematically more deprived in higher numbers of dimensions. Similarly, SC/ST/OBC SMI-poverty associations were found to be consistent across dimensions of poverty regardless of the threshold for multidimensional poverty. These findings 
Table 6 Logistic model for association between multidimensional poverty, stigma and severe mental illness (SMI)

\begin{tabular}{|c|c|c|c|c|}
\hline & \multicolumn{2}{|c|}{ Unadjusted model } & \multicolumn{2}{|c|}{ Adjusted model } \\
\hline & OR & $95 \% \mathrm{Cl}$ & OR & $95 \% \mathrm{Cl}$ \\
\hline Family participation (no participation) & 2.92 & 2.16 to 3.93 & 2.61 & 1.27 to 5.31 \\
\hline SMI (controls) & 2.20 & 1.67 to 2.89 & 2.07 & 1.25 to 3.41 \\
\hline Women (men) & 2.17 & 1.65 to 2.83 & 1.88 & 1.36 to 2.58 \\
\hline SC/ST/OBC (higher caste) & 2.06 & 1.56 to 2.70 & 2.39 & 1.39 to 4.08 \\
\hline Age (in year) & 0.99 & 0.97 to 0.99 & 0.98 & 0.96 to 0.99 \\
\hline \multicolumn{5}{|l|}{ Interaction terms } \\
\hline No participation×SMI (participation×controls) & & & 6.38 & 3.49 to 11.6 \\
\hline No participation×SC/ST/OBC (participation×high caste) & & & 4.86 & 2.19 to 10.7 \\
\hline No participation $\times$ women (participation $\times$ men) & & & 4.63 & 2.60 to 8.21 \\
\hline No participation×women×SMI (participation $\times$ malexcontrols) & & & 9.62 & 5.58 to 16.5 \\
\hline No participation $\times S C / S T / O B C \times S M I$ (participation $\times$ high caste $\times$ controls) & & & 7.36 & 3.94 to 13.7 \\
\hline
\end{tabular}

strongly suggest that stigma linked to various marginalised groups have the power to accelerate and intensify exclusion and related discrimination. For women, SMI can negatively impact well-being in two ways. First, SMI limits women from fulfilling family and social roles, leading to these women being considered a burden for the family. This is true despite studies such as the Indian study of women with schizophrenia abandoned by their husbands who expressed the desire to work to support themselves. ${ }^{58}$ Second, traditional beliefs (punishment for previous lives, evil eye/curse), as well as negative lay attitudes on causes and behaviours, lead to increased discrimination of and sometimes violence against SMIs, particularly for women. ${ }^{59}$

Our study finds that SC/ST/OBC and poverty further compound SMI. Discrimination linked to caste in accessing education or employment has been a leitmotif in modern India and only partially addressed through constitutional provisions and reservation policies. Caste discrimination still results in scant employment opportunities, less access to secondary and higher education-key for salaried public and private jobs, perpetuating powerlessness, traditional forms of dominance and oppression, inequalities, lower living standards among SC/ST/ $\mathrm{OBC}$ as a entrenched social identity in India. ${ }^{60} 61$ This situation is even more catastrophic for PSMI from $\mathrm{SC} / \mathrm{ST} / \mathrm{OBC}$.

It is clear that a 'negative feedback loop' exists: stigma against SMI, particularly for SC/ST/OBC and women, is a strong predictor of persistent poverty. Moreover, stigma strongly bears on intensity of poverty. Stigma leads to difficulty for PSMI in finding and keeping a job, and this also increases the perceived burden of SMI by family members. In turn, this deprivation on various dimensions erodes self-esteem and brings shame and acceptance of discriminatory attitudes. ${ }^{62}$ These compounding factors may result in a worsening of mental illness.

Beyond the PSMI, stigma and discrimination have a negative effect on family members and caregivers who often feel ashamed, embarrassed or unable to cope with the stigma. ${ }^{58}{ }^{63-67}$ While there have been campaigns and policies to address discrimination against $\mathrm{SC} / \mathrm{ST} / \mathrm{OBC}$ and women in India, no large-scale awareness campaign has ever addressed the prejudice and discrimination faced by PSMIs.

This study has some limitations. First, a potential limitation is that we measured experienced discrimination with a single-item question on exclusion from family decision rather than a multiple-item scale. There was not a specific formalised psychometrically validated measure of experienced stigma available focusing on the scope and content of discrimination before the Discrimination and Stigma Scale made available after our study was carried out. ${ }^{10}$ Other factors may also explain exclusion from family decisions, particularly symptomatic patients' disruptive behaviour. To account for this issue, we selected a large sample of PSMI at Dr RML hospital representing a wide variety of severity of symptoms. Yet all outpatients were successfully treated and mostly in follow-up, and therefore not symptomatic at the time of the survey. Despite treatment, SMI in cases was significantly associated with our measure of stigma compared with controls, showing that 'pre-existing beliefs' or stereotypes linked to past experience with the mental illness were critical to the activation of the discrimination process rather than the current mental health status of the person. ${ }^{68}$ Second, it was not possible to establish the direction of the association between poverty and SMI; poverty can be a cause as well as a consequence of SMI. Third, SMI was diagnosed within a psychiatric department of a free government hospital. Research indicates the poorest members of society may still not access such services, even when free, possibly introducing a selection bias in our sample. ${ }^{69}$ Additionally, PSMI not receiving medical treatment might be even more marginalised, at greater risk of poverty than those receiving healthcare. Thus the sampling bias might have underestimated association between SMI, stigma and poverty. Finally, due to the large sample size we could not evaluate each control using detailed diagnostic psychiatric questionnaires but only screen them for major mental disorders. 


\section{CONCLUSION}

Our study provides evidence that mental health professionals must incorporate an understanding of multidimensional poverty stressors as well as address family and community dynamics. Where resources are limited, medical professionals would benefit from working with public health and disability networks to weaken persistent stigma against SMI. Policies promoting employment support for PSMI (notably through reservations or fair employment policies, and access to credit) are critically important. The implications of our findings go beyond medical and public health and link mental health to international development. Promoting employment and fighting social stigma for PSMI not only mitigates the impact of illness for some but appears to be a central concern of global poverty.

\section{Author affiliations}

${ }^{1}$ Brown School, Washington University in St. Louis, St. Louis, Missouri, USA

${ }^{2}$ Program in Occupational Therapy, School of Medicine, Washington

University in St. Louis, St Louis, Missouri, USA

${ }^{3}$ Department of Psychiatry \& De-addiction Services, Resource Centre for Tobacco Control, PGIMER- Dr. Ram Manohar Lohia Hospital, New Delhi, India ${ }^{4}$ Nijmegen School of Management, Radboud University, Nijmegen, Netherlands

${ }^{5}$ Leonard Cheshire Chair, Director, Leonard Cheshire Disability \& Inclusive Development Centre, Division of Epidemiology and Public Health University College London, London, UK

${ }^{6}$ UCL School of Life and Medical Sciences, University College London, London, UK

Contributors Study designed by JFT, SD, PB and SJ. Data collection supervised by SV, NM, SN and SD. Literature review by PB with JFT. Data analysis by JK and JFT. Data interpretation and writing by JFT and PB, and revised by SD and NG. All authors contributed to the final manuscript. J-FT had full access to all data and takes final responsibility for publication submission.

Funding Funded by DFID through the Cross-Cutting Disability Research Programme, Leonard Cheshire Disability and Inclusive Development Centre, University College London (GB-1-200474).

\section{Competing interests None.}

Ethics approval University College London Research Ethics Committee and the Dr Ram Manohar Lohia Hospital Institutional Ethics Committee.

Provenance and peer review Not commissioned; externally peer reviewed.

Data sharing statement Extra data can be accessed via the Dryad digital repository at http://doi.org/10.5061/dryad.NNNNN with doi:10.5061/dryad.j167m.

Open Access This is an Open Access article distributed in accordance with the Creative Commons Attribution Non Commercial (CC BY-NC 4.0) license, which permits others to distribute, remix, adapt, build upon this work noncommercially, and license their derivative works on different terms, provided the original work is properly cited and the use is non-commercial. See: http:// creativecommons.org/licenses/by-nc/4.0/

\section{REFERENCES}

1. Lozano R, Naghavi M, Foreman K, et al. Global and regional mortality from 235 causes of death for 20 age groups in 1990 and 2010: a systematic analysis for the Global Burden of Disease Study 2010. Lancet 2012;380:2095-128.

2. World Health Organization. Mental health and development: targeting people with mental health conditions as a vulnerable group. 2010

3. Vos T, Flaxman AD, Naghavi M, et al. Years lived with disability (YLDs) for 1160 sequelae of 289 diseases and injuries 1990?2010: a systematic analysis for the Global Burden of Disease Study 2010. Lancet 2012;380:2163-96.
4. Whiteford HA, Degenhardt L, Rehm J, et al. Global burden of disease attributable to mental and substance use disorders: findings from the Global Burden of Disease Study 2010. Lancet 2013;382: 1575-86.

5. Kleinman A, Hall-Clifford R. Stigma: a social, cultural and moral process. J Epidemiol Community Health 2009;63:418-19.

6. Boyce W, Raja S, Patranabish R, et al. Occupation, poverty and mental health improvement in Ghana. ALTER Eur J Disabil Res 2009;3:233-44.

7. Elwan A. Poverty and disability: a survey of the literature. Washington, DC: Social Protection Advisory Service, 1999.

8. Groce N, Kett M, Lang R, et al. Disability and Poverty: the need for a more nuanced understanding of implications for development policy and practice. Third World Q 2011;32:1493-513.

9. Skeen S, Lund C, Kleintjes S, et al. Meeting the Millennium Development Goals in Sub-Saharan Africa: what about mental health? Int Rev Psychiatry 2010;22:624-31.

10. Brohan E, Clement S, Rose D, et al. Development and psychometric evaluation of the Discrimination and Stigma Scale (DISC). Psychiatry Res 2013;208:33-40.

11. Draine J. Mental health, mental illnesses, poverty, justice, and social justice. Am J Psychiatr Rehabil 2013;16:87-90.

12. Fone D, Greene G, Farewell D, et al. Common mental disorders, neighbourhood income inequality and income deprivation: small-area multilevel analysis. Br J Psychiatry 2013;202:286-93.

13. Li N, Pang L, Du W, et al. Association between poverty and psychiatric disability among Chinese population aged 15-64 years. Psychiatry Res 2012;200:917-20.

14. Chatteriee P. Economic crisis highlights mental health issues in India. Lancet 2009;373:1160-1.

15. Kuruvilla A, Jacob KS. Poverty, social stress \& mental health. Indian J Med Res 2007;126:273-8.

16. Das J, Do QT, Friedman J, et al. Mental health and poverty in developing countries: Revisiting the relationship. Soc Sci Med 2007;65:467-80.

17. de Menil V, Osei A, Douptcheva N, et al. Symptoms of common mental disorders and their correlates among women in Accra, Ghana: a population-based survey. Ghana Med J 2012;46:95-103.

18. Link BG, Phelan JC. Conceptualizing stigma. Annu Rev Sociol 2001:27:363-85.

19. Thornicroft G, Rose D, Kassam A, et al. Stigma: ignorance, prejudice or discrimination? Br J Psychiatry 2007;190:192-3.

20. Ilic M, Reinecke J, Bohner G, et al. Belittled, avoided, ignored, denied: assessing forms and consequences of stigma experiences of people with mental illness. Basic Appl Soc Psychol 2013;35:31-40.

21. Wing JK, Agrawal N. Concepts and classification of schizophrenia. In: Hirsch SR, Weinberger DR. eds. Schizophrenia. Oxford: Wiley-Blackwell, 2003:3-15.

22. Corrigan PW, Markowitz FE, Watson AC. Structural levels of mental illness stigma and discrimination. Schizophr Bull 2004;30:481-91.

23. Link BG, Struening EL, Neese-Todd S, et al. The consequences of stigma for the self-esteem of people with mental illnesses. Psychiatr Serv 2001;52:1621-6.

24. Watson AC, Corrigan P, Larson JE, et al. Self-stigma in people with mental illness. Schizophr Bull 2007;33:1312-18.

25. Rüsch N, Angermeyer MC, Corrigan PW. Mental illness stigma: concepts, consequences, and initiatives to reduce stigma. Eur Psychiatry 2005;20:529-39.

26. Wahl OF. Stigma as a barrier to recovery from mental illness. Trends Cogn Sci 2012;16:9-10.

27. Link BG, Phelan JC. Stigma and its public health implications. Lancet 2006;367:528-9.

28. Link BG, Yang LH, Phelan JC, et al. Measuring mental illness stigma. Schizophr Bull 2004;30:511-41.

29. Hatzenbuehler ML, Phelan JC, Link BG. Stigma as a fundamental cause of population health inequalities. Am J Public Health 2013;103:813-21.

30. Crabb J, Stewart RC, Kokota D, et al. Attitudes towards mental illness in Malawi: a cross-sectional survey. BMC Public Health 2012;12:541.

31. Gureje O, Lasebikan VO, Ephraim-Oluwanuga O, et al. Community study of knowledge of and attitude to mental illness in Nigeria. $\mathrm{Br} J$ Psychiatry 2005;186:436-41.

32. Jadhav S, Littlewood R, Ryder AG, et al. Stigmatization of severe mental illness in India: against the simple industrialization hypothesis. Indian J Psychiatry 2007;49:189-94.

33. Ngui $E$, Khasakhala A, Ndetei D, et al. Mental disorders, health inequalities and ethics: a global perspective. Int Rev Psychiatry 2010;22:235-44. 
34. Ssebunnya J, Kigozi F, Lund C, et al. Stakeholder perceptions of mental health stigma and poverty in Uganda. BMC Int Health Hum Rights 2009;9:5.

35. Phelan JC. Genetic bases of mental illness-A cure for stigma? Trends Neurosci 2002;25:430-1.

36. Khandelwal SK, Pattanayak RD. Fight against Stigma. In: Chavan BS, Gupta N, Arun P, Sidana AK, Jadhav S. eds. Comprehensive textbook on community psychiatry in India. Delhi: Jaypee Brothers, 2012:334-44.

37. Alkire S, Foster J. Counting and multidimensional poverty measurement. J Public Econ 2011;95:476.

38. World Health Organization. ICD-10 classification of mental and behavioral disorders: clinical descriptions and diagnostic guidelines. Geneva: World Health Organisation, 1992.

39. Dupont WD, Plummer WD Jr. Power and sample size calculations. A review and computer program. Controlled Clin Trials 1990;11:116-28.

40. DeVellis RF. Scale development: theory and applications. Vol 26. Thousand Oaks: Sage, 2012.

41. Sen AK. Capabilities, lists, and public reason: continuing the conversation. Feminist Econ 2004:10:77-80.

42. Ravallion M, Chen S, Sangraula P. Dollar a day revisited. World Bank Econ Rev 2009:23:163-84.

43. Shrivastava A, Johnston M, Thakar M, et al. Origin and impact of stigma and discrimination in schizophrenia-patients' perception: Mumbai study. Stigma Res Action 2011:1:67-72.

44. Loganathan S, Murthy RS. Living with schizophrenia in India: gender perspectives. Transcult Psychiatry 2011;48:569-84.

45. Corrigan PW, Miller FE. Shame, blame, and contamination: a review of the impact of mental illness stigma on family members. J Ment Health 2004;13:537-48.

46. Karnieli-Miller O, Perlick DA, Nelson A, et al. Family members' of persons living with a serious mental illness: experiences and efforts to cope with stigma. J Ment Health 2013;22:254-62.

47. Larson JE, Corrigan P. The stigma of families with mental illness. Acad Psychiatry 2008;32:87-91.

48. Bruckner T, Catalano RA. Economic antecedents of sudden infant death syndrome. Ann Epidemiol 2006;16:415-22.

49. Eskenazi B, Marks AR, Catalano R, et al. Low birthweight in New York city and upstate New York following the events of September 11th. Hum Reprod 2007;22:3013-20.

50. Planning Commission. Poverty estimates for social groups: 2004-05 and 2011-12. New Delhi, 2013.

51. Olinto P, Beegle K, Sobrado C, et al. The State of the Poor: where are the poor, where is extreme poverty harder to end, and what is the current profile of the world's poor? Econ Premise 2013;125:1-8.
52. Kohler Riessman C. Stigma and everyday resistance practices: childless women in South India. Gender Soc 2000;14:111-35.

53. Jaspal R. Caste, social stigma and identity processes. Psychol Dev Soc 2011;23:27-62.

54. Biemer PP. ed. Measurement errors in surveys. New York: John Wiley and Sons, 1991.

55. Biemer PP, Lyberg LE. Introduction to survey quality. Hoboken: John Wiley \& Sons, 2003.

56. Das J, Das RK, Das V. The mental health gender-gap in urban India: patterns and narratives. Soc Sci Med 2012;75:1660-72.

57. Das J, Quy-Toan Do Q, Friedman J, et al. Mental health and poverty in developing countries: revisiting the relationship. Soc Sci Med 2007:65:467-80.

58. Thara R, Kamath S, Kumar S. Women with schizophrenia and broken marriages-Doubly disadvantaged? Part I: Patient perspective. Int J Soc Psychiatry 2003;49:225-32.

59. Human Rights Watch. "Treated Worse than Animals". Abuses against women and girls with psychosocial or intellectual disabilities in institutions in India. Human Rights Watch, 2014.

60. Jeffrey C, Jeffery P, Jeffery R. Reproducing difference? Schooling, jobs, and empowerment in Uttar Pradesh, India. World Dev 2005;33:2085-101.

61. Kijima Y. Caste and tribe inequality: evidence from India, 1983-1999. Econ Dev Cult Change 2006;54:369-404.

62. Corrigan PW, Larson JE, Rüsch N. Self-stigma and the "why try" effect: Impact on life goals and evidence-based practices. World Psychiatry 2009;8:75-81.

63. Thara R, Kamath S, Kumar S. Women with schizophrenia and broken marriages-Doubly disadvantaged? Part II: Family perspective. Int J Soc Psychiatry 2003;49:233-40.

64. Brady N, McCain GC. Living with schizophrenia: a family perspective. Online J Issues Nurs 2005;10:7.

65. Lee S, Lee MTY, Chiu MYL, et al. Experience of social stigma by people with schizophrenia in Hong Kong. Br J Psychiatry 2005;186:153-7.

66. Yang LH, Purdie-Vaughns V, Kotabe $\mathrm{H}$, et al. Culture, threat, and mental illness stigma: identifying culture-specific threat among Chinese-American groups. Soc Sci Med 2013;88:56-67.

67. Yang LH, Pearson VJ. Understanding families in their own context: schizophrenia and structural family therapy in Beijing. J Fam Ther 2002;24:233-57.

68. Link BG, Cullen F, Frank J, et al. The social rejection of former mental patients: understanding why labels matter. AJS 1987;92:1461-500.

69. Murali V, Oyebode F. Poverty, social inequality and mental health. Adv Psychiatr Treat 2004;10:216-24. 